\title{
Plasminogen activator inhibitor-1 is a critical downstream target of p53 in the induction of replicative senescence
}

\author{
Roderik M. Kortlever ${ }^{1}$, Paul J. Higgins ${ }^{2}$ and René Bernards ${ }^{1,3}$
}

p53 limits the proliferation of primary diploid fibroblasts by inducing a state of growth arrest named replicative senescence - a process which protects against oncogenic transformation and requires integrity of the p53 tumour suppressor pathway ${ }^{1-3}$. However, little is known about the downstream target genes of p53 in this growth-limiting response. Here, we report that suppression of the p53 target gene encoding plasminogen activator inhibitor-1 (PAI-1) by RNA interference (RNAi) leads to escape from replicative senescence both in primary mouse embryo fibroblasts and primary human BJ fibroblasts. $P A I-1$ knockdown results in sustained activation of the PI(3)K-PKB-GSK3 $\beta$ pathway and nuclear retention of cyclin $\mathrm{D} 1$, consistent with a role for PAI-1 in regulating growth factor signalling. In agreement with this, we find that the $\mathrm{PI}(3) \mathrm{K}-$ PKB-GSK3 $\beta$-cyclin D1 pathway is also causally involved in cellular senescence. Conversely, ectopic expression of PAI-1 in proliferating p53-deficient murine or human fibroblasts induces a phenotype displaying all the hallmarks of replicative senescence. Our data indicate that PAI-1 is not merely a marker of senescence, but is both necessary and sufficient for the induction of replicative senescence downstream of p53.

Primary murine fibroblasts activate the $\mathrm{p} 19^{\mathrm{ARF}}-\mathrm{p} 53$ tumour suppressor pathway during prolonged culturing in vitro, which induces a postmitotic state referred to as replicative senescence. Senescence can be overcome by loss of either p19 ${ }^{\mathrm{ARF}}$, p53 or the combined loss of all three retinoblastoma family proteins ${ }^{1,2}$. Proliferation of fibroblasts is induced by growth factors which activate cyclin-dependent kinases (CDKs), and in turn inactivate $\mathrm{pRb}$ 's growth-limiting ability ${ }^{2}$, a G1 cell-cycle checkpoint that is often deregulated in cancer ${ }^{3}$. It is unclear which of the many downstream p53-target genes is responsible for the p53-dependent induction of replicative senescence. An attractive candidate is the CDK inhibitor $p 21^{C I P 1}$. However, mouse embryo fibroblasts (MEFs) knocked out for $p 21^{C I P 1}$ are not immortal ${ }^{4}$.

Here, we identify an unexpected causal role for the urokinase type plasminogen activator (uPA)-PAI-1 system in the induction of replicative senescence. The serpin and extra-cellular matrix (ECM)associated protein PAI-1 is a direct target of p53 (ref. 5, 6), is upregulated in ageing fibroblasts in vivo and in vitro, and is considered a marker of replicative senescence ${ }^{7-9}$. PAI- 1 inhibits the activity of the secreted protease uPA by forming a stable complex. uPA expression can cause cells to progress through G1 into $S$ phase ${ }^{10}$, most likely through activating a mitogenic signalling cascade by increasing the bioavailability of growth factors.

To investigate the role of PAI- 1 in replicative senescence, two independent retroviral vectors were generated that targeted murine PAI-1 for suppression through $\mathrm{RNAi}^{11}$. When primary MEFs were infected with either PAI-1 knockdown (kd) construct (PAI- $1^{k d} I$ or PAI- $\left.1^{k d} I I\right)$, bypass of senescence was observed in a colony formation assay (Fig. 1a). As inhibition of PAI-1 expression leads to activation of $\mathrm{uPA}^{12,13}$, we asked whether overexpression of uPA also caused immortalisation. Retrovirusmediated over-expression of pro-uPA was as efficient as PAI-1 knockdown in causing immortalisation of MEFs (Fig. 1a). To assess PAI-1 levels in infected MEFs, $p 53^{k d}, P A I-1^{k d}$ or $u P A$ overexpressing cells were serially passaged until they had become post-senescent at passage 9 (P9) (that is, when control MEFs were senescent) and observed a significant reduction in PAI-1 mRNA expression in PAI- $1^{k d}$ MEFs by quantitative RT-PCR (QRT-PCR; Fig. 1b). As PAI-1 is a transcriptional p53 target $^{5,6}$ and $\mathrm{p} 53$ is activated during replicative senescence, $P A I-1$ is highly expressed in senescent $\mathrm{MEFs}^{9}$. Accordingly, P9 MEFs expressed more PAI-1 than P3 or $p 53^{k d}$ cells, which had comparable PAI-1 mRNA levels (Fig. 1b). uPA activity is downstream of PAI-1 and p53, and consequently immortal cells overexpressing uPA have PAI-1 expression levels similar to those observed in P9 MEFs (Fig. 1b). When examined in a long-term cell proliferation assay, PAI- ${ }^{\mathrm{kd}}$ also extended the proliferative capacity of MEFs far beyond that of wild-type cells (see Supplementary Information, Fig. S1a). Spontaneous immortalisation of MEFs can be caused either by mutation of $\mathrm{p} 53$ or by loss of p19 $9^{\mathrm{ARF}}$ expression ${ }^{14-16}$, which was not observed in PAI- $1^{\mathrm{kd}}$ cells as judged by their normal p53dependent DNA-damage response (see Supplementary Information, Fig. S1b). As p19 ${ }^{\mathrm{ARF}}$ levels in PAI- $1^{\mathrm{kd}}$ cells are comparable with those observed in wild-type senescent cells, we concluded that p19ARF

${ }^{1}$ Division of Molecular Carcinogenesis and Center for Biomedical Genetics, The Netherlands Cancer Institute, Plesmanlaan 1211066 CX Amsterdam, The Netherlands. ${ }^{2}$ Center for Cell Biology \& Cancer Research, Albany Medical College, MC-165, 47 New Scotland Avenue, Albany, NY 12208, USA.

${ }^{3}$ Correspondence should be addressed to R.B. (e-mail: r.bernards@nki.nl) 
a

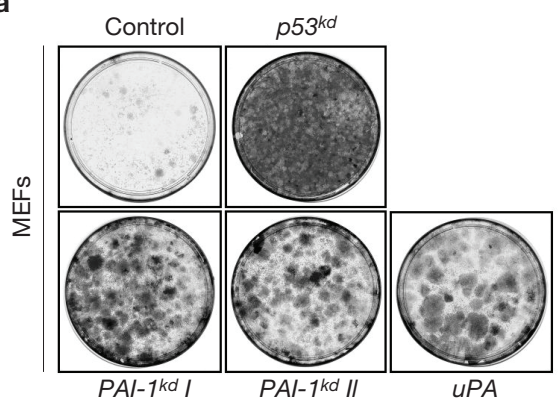

b

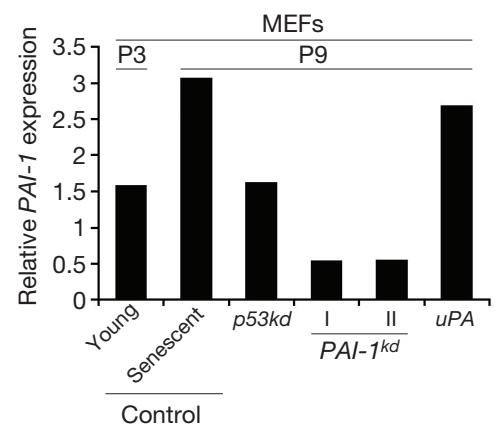

c

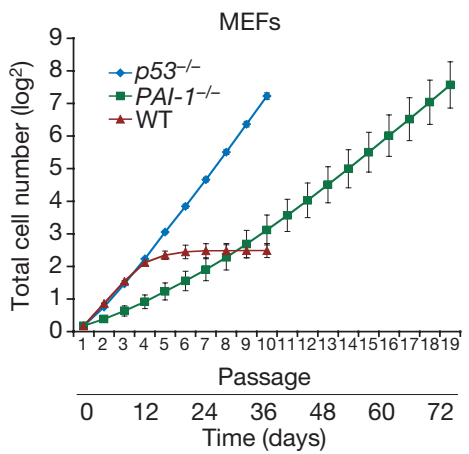

d

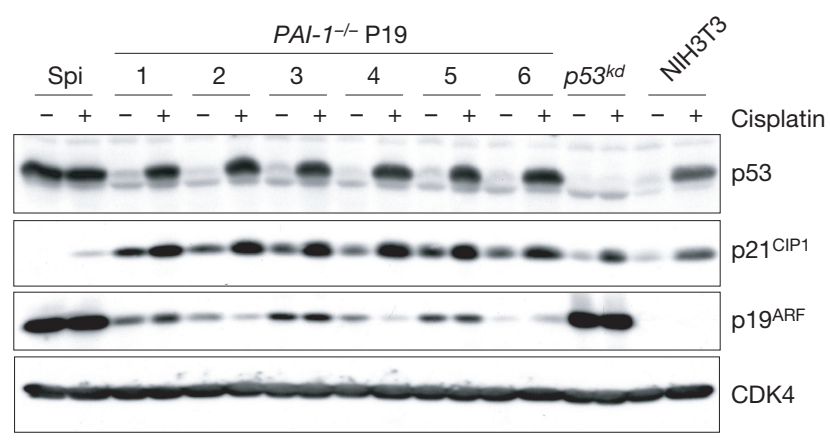

Figure 1 PAl-1 loss induces senescence-bypass in primary mouse fibroblasts. (a) Colony formation assay in primary MEFs overexpressing the indicated constructs. A knockdown vector for $p 53$ was used as a positive control. (b) Relative PAl-1 expression analysed by QRT-PCR on extracts from the indicated post-senescent polyclonal cell lines. P3 are young passage 3 and P9 are senescent passage 9 MEFs. (c) Growth curves of PAI-1-1, $p 53^{--}$and wild-type (WT) MEFs. For each genotype the mean \pm s.d. of six independent cultures is shown. (d) Western blot analysis of a spontaneously immortal line (spi), six independent PAI-1-- passage 19 (P19), $p 53^{\text {kd }}$ and $p 16^{\text {INK4A }}-p 19^{A R F}-$ deficient immortal NIH3T3 cell lines showing status of p53 and its targets p1 $19^{A R F}$ and $p 21^{\mathrm{CIP1}}$ after cisplatin-induced DNA damage. CDK4 is a loading control. Uncropped full scans are shown in the Supplementary Information. expression is not lost after knockdown of $P A I-1$. Consistent with these observations, $P A I-1$ knockout $\left(P A I-1^{-/-}\right)$MEFs proliferated well beyond the senescence checkpoint, albeit at a slower rate than $p 53^{-/-}$MEFs (Fig. 1c). Importantly, six independent immortal PAI-1/-- MEF cell lines showed normal p53 function after DNA-damage exposure (Fig. 1d).

Next, we sought to understand the molecular pathway(s) involved in the immortalisation of MEFs after PAI-1 knockdown or UPA overexpression. The tumour suppressors $\mathrm{p} 16^{\mathrm{INK} 4 \mathrm{~A}}$ and $\mathrm{p} 21^{\mathrm{CIP} 1}$ were induced in P9 MEFs and immortal PAI- $1^{\mathrm{kd}}$ or uPA overexpressing cells, indicating that the senescence-stress pathway is activated in these MEFs (Fig. 2a). Interestingly, a sharp increase in cyclin D1 levels were observed in both non-proliferating P9 and proliferating PAI- $1^{\mathrm{kd}}$ or $\mathrm{UPA}$ overexpressing MEFs, which may neutralize the high levels of p21 ${ }^{\text {CIP1 }}$ (Fig. 2a). We asked whether signalling through $\mathrm{PI}(3) \mathrm{K}, \mathrm{PKB}$ (also known as AKT) and GSK $3 \beta$ was involved. Activation of $\mathrm{PI}(3) \mathrm{K}$ and subsequent full activation of $\mathrm{PKB}$ by phosphorylation on Ser 473 leads to an inhibitory phosphorylation of GSK3 $\beta$ on Ser 9 by $\mathrm{PKB}^{17,18}$. GSK3 $\beta$ controls cyclin D1 localization and degradation through an inhibitory phosphorylation on Thr 286 and loss of this inhibitory phosphorylation protects cyclin D1 from nuclear exclusion and degradation ${ }^{19}$. Therefore, mitogenic signalling through PI(3)K-PKB-GSK3 $\beta$ influences cyclin D1 stability and its nuclear activity, leading to cell-cycle progression ${ }^{2}$. uPA induces growth factor-related $\mathrm{PI}(3) \mathrm{K}-\mathrm{PKB}$ signalling ${ }^{20}$ and, as a result, uPA activity may result in nuclear retention of cyclin D1 by inducing loss of GSK3 $\beta$ activity through phosphorylation on Ser 9. When cyclin D1 localization was determined in ageing MEFs, a striking but gradual nuclear exclusion of cyclin D1 was observed (Fig. 2b), which correlated with the decline in growth rate (note that wild-type MEFs became fully senescent at passage 8; see Supplementary Information, Fig. S2a, as confirmed by staining for senescence-associated acidic $\beta$-galactosidase ${ }^{21}$, SA- $\beta$-Gal; data not shown). Furthermore, during serial passaging, wild-type MEFs show a progressive decline in $\mathrm{PKB}$ activation by loss of phosphorylation and a gradually increased GSK $3 \beta$ activation by loss of inhibitory phosphorylation (Fig. 2c). In contrast, immortal PAI- $1^{\mathrm{kd}}$ or uPA overexpressing MEFs had sustained PKB-GSK3 $\beta$ signalling (see Supplementary Information, Fig. S2b). We therefore concluded that during replicative senescence cyclin D1 is excluded from the nucleus and stabilized in the cytosol, correlating with decreased growth-rate and downregulation of PKB-GSK3 $\beta$ signalling. The high levels of cyclin D1 found in senescent cells (Fig. 2a) were unexpected because GSK3 $\beta$ activity induces not only nuclear exclusion, but also the turnover of cyclin D1 (ref. 19). Significantly, high levels of cyclin D1 were also observed in senescent human BJ fibroblasts (Fig. 5c). Apparently, the turnover of cyclin D1 is different in senescent cells as compared with cycling NIH3T3 cells ${ }^{19}$.

We next examined whether immortalisation of MEFs by PAI- 1 knockdown may be the result of activated PI(3)K-PKB-GSK3 $\beta$ signalling. Primary MEFs were retrovirally transduced with constitutively active mutants of PI(3)K (p110 $\alpha^{\mathrm{CAAX}}$; Ca-PI(3)K) or PKB (Myr-PKB; Ca-PKB), a retroviral knockdown short hairpin RNA (shRNA) construct for GSK3 $\beta$, or retroviral expression constructs for wild-type cyclin D1 (D1) or nondegradable cyclin D1 (T286A-cyclin D1; TA-D1), and determined their immortalizing potential in a colony-formation assay. The TA-D1 mutant 
is refractory to phosphorylation by GSK3 $\beta$ and is therefore constitutively nuclear $^{19}$. We found that Ca-PI(3)K, Ca-PKB, GSK3 $3 \beta^{\mathrm{kd}}$ or TA-D1 (but not wild type D1) are individually capable of immortalizing wild-type MEFs (Fig. 3a). Furthermore, no loss of p19 ${ }^{\mathrm{ARF}}$ expression or evidence for mutation of 553 was found in any of the immortalised MEFs (data not shown). When tested in a long-term proliferation assay, overexpression of Ca-PI(3)K, Ca-PKB, GSK3 $\beta^{\mathrm{kd}}$ or TA-D1 (but not wild type D1) also induced a bypass of senescence in MEFs (Fig. 3b). Again, immortalisation was not accompanied by loss of p19 ${ }^{\mathrm{ARF}}$ or p53 function (data not shown). As previously observed in PAI- ${ }^{\mathrm{kd}}$ or uPA overexpressing MEFs (Fig. 2a), induction of $\mathrm{p} 21^{\mathrm{CIP} 1}$ protein levels in the post-senescent polyclonal cell lines expressing a Ca-PI(3)K, Ca-PKB, GSK3 $\beta^{\mathrm{kd}}$, or TA-D1 construct was noted (see Supplementary Information, Fig. S2c). Furthermore, high PKB-GSK3 $\beta$ signalling was observed in Ca-PI(3)K or Ca-PKB overexpressing cells and reduced GSK3 $\beta$ expression in GSK3 $\beta^{\mathrm{kd}}$ cells (see Supplementary Information, Fig. S2d). Our results suggest that enforced constitutive activation of $\mathrm{PI}(3) \mathrm{K}-\mathrm{PKB}$ signalling, reduction of GSK $3 \beta$ activity or nuclear retention of cyclin D1, is sufficient to bypass senescence in MEFs downstream of p53. Accordingly, immunofluorescence microscopy analysis of post-senescent polyclonal cell lines of MEFs immortalised with the various constructs used in this study revealed nuclear localization of endogenous cyclin D1 when compared with senescent wild-type or HA-tagged cyclin D1 expressing MEFs (Fig. 3c and see Supplementary Information, Fig. S2e).

To examine whether reduction of $\mathrm{PI}(3) \mathrm{K}-\mathrm{PKB}-\mathrm{GSK} 3 \beta$ signalling is sufficient for the induction of senescence, antagonists of this mitogenic signalling route were overexpressed in $p 53$-depleted cells. Retroviral cDNA expression constructs were generated for human PAI-1 (which is not targeted by the mouse PAI- $1^{\mathrm{kd}}$ vectors), mouse PTEN and GSK $3 \beta$. PTEN is a potent tumour suppressor often deleted in cancer that blocks the activation of $\mathrm{PI}(3) \mathrm{K}^{22}$ and exerts its effect in part by regulating nuclear availability of cyclin D1 (ref. 23). When overexpressed in $p 53^{k d}$ or PAI$1^{k d}$ cells, PAI-1, PTEN and GSK3 $\beta$ were all individually able to induce senescence, as observed by a flat-cell morphology and positive staining for SA- $\beta$-Gal. (Fig. $4 \mathrm{a}-\mathrm{d}$ ). To test whether cyclin D1 is an essential target downstream of PAI-1, PAI-1 was overexpressed in $p 53^{-/-}$MEFs, MEFs overexpressing TA-D1, or pocket-protein deficient triple knockout cells ( $\mathrm{pRb}^{-/-}-\mathrm{p} 107^{-/-}-\mathrm{p} 130^{-/-}$; TKO). The immortal TKO controls lack retinoblastoma family function and therefore have sustained E2F activity ${ }^{24,25}$. In normal fibroblasts $\mathrm{pRb}$ (family)-E2F-mediated repression is required for cell-cycle exit in response to p19 ${ }^{\mathrm{ARF}}$-p 53 activation ${ }^{26}$. Overexpression of TA-D1 in MEFs may therefore resemble the phenotype seen in TKO cells by blocking retinoblastoma family function. Figure $4 \mathrm{e}$ shows that PAI-1 induced an arrest in $p 53^{-/-}$cells, but not when these cells also expressed TA-D1 or were pocket-protein deficient. These results suggest that in the presence of a wild-type cyclin D1 protein, PAI-1 is able to induce an arrest, but not when cyclin D1 is constitutively nuclear and insensitive to GSK3 $\beta$.

The senescence response of human fibroblasts is, in the first instance, primarily dependent on p53 (M1 checkpoint) and, as in MEFs, PAI-1 is upregulated during ageing and is a marker of senescence in these cells $\mathrm{s}^{7,27}$. When primary human BJ fibroblasts were infected with either one of two independent human-specific PAI- 1 knockdown constructs (PAI- $1^{\mathrm{kd}}$ I or PAI- ${ }^{\mathrm{kd}}$ II) an M1 senescence-bypass was observed as judged in a long-term growth assay (Fig. 5a). As in MEFs, overexpression of uPA also induced a bypass of senescence in primary BJ cells, albeit with lower a

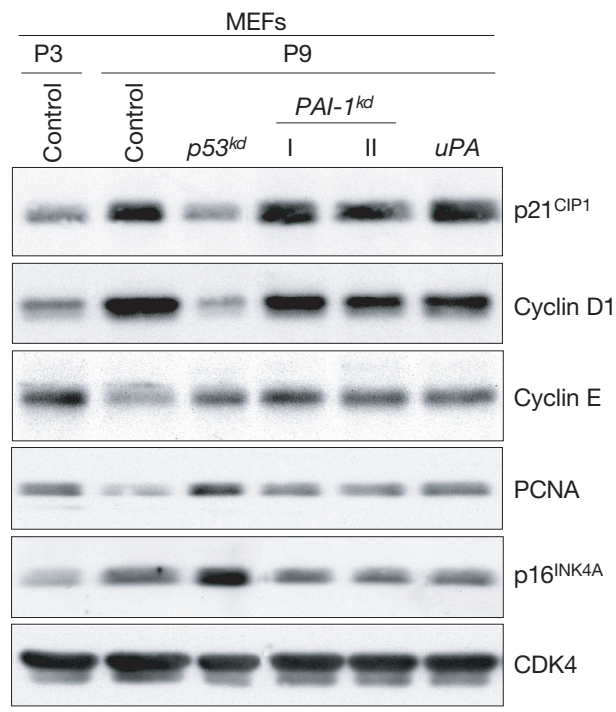

b

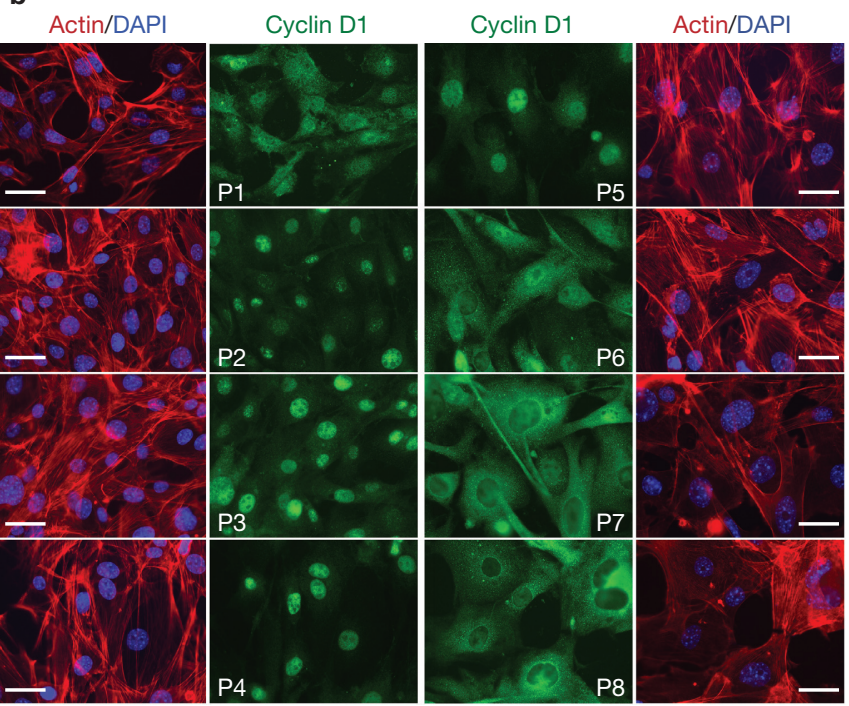

C

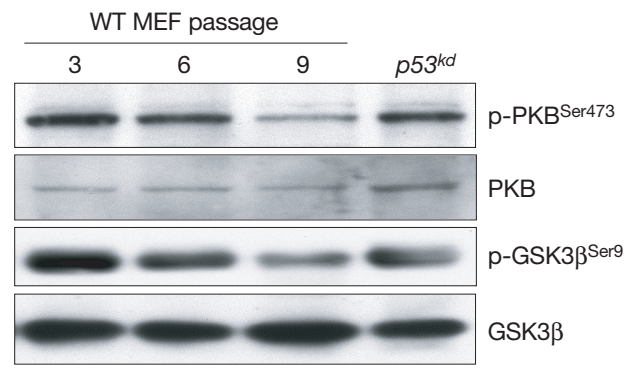

Figure 2 MEFs reduce PKB activation and exclude cyclin D1 from the nucleus during replicative senescence. (a) Western blot analysis of P3, P9, $p 53^{k d}, P A /-1^{k d}$ or $U P A$ overexpressing MEFs for cell-cycle related proteins. PCNA and CDK4 are proliferation and loading controls, respectively. (b) Qualitative immunofluorescence microscopy analysis of serially passaged MEFs, (P1-P8), for cyclin D1 expression. The scale bar represents $50 \mu \mathrm{m}$. (c) Expression of phosphorylated PKB or GSK3 $\beta$ related to unphosphorylated fraction of the same proteins in P3, P6 and P9 MEFs and post-senescent $p 53^{k d}$ cells as analysed by western blot. 


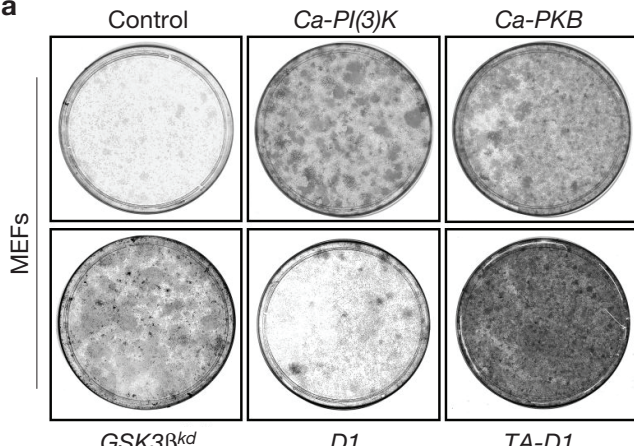

1 week

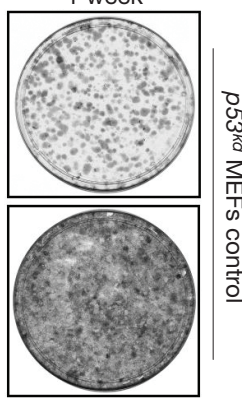

3 weeks
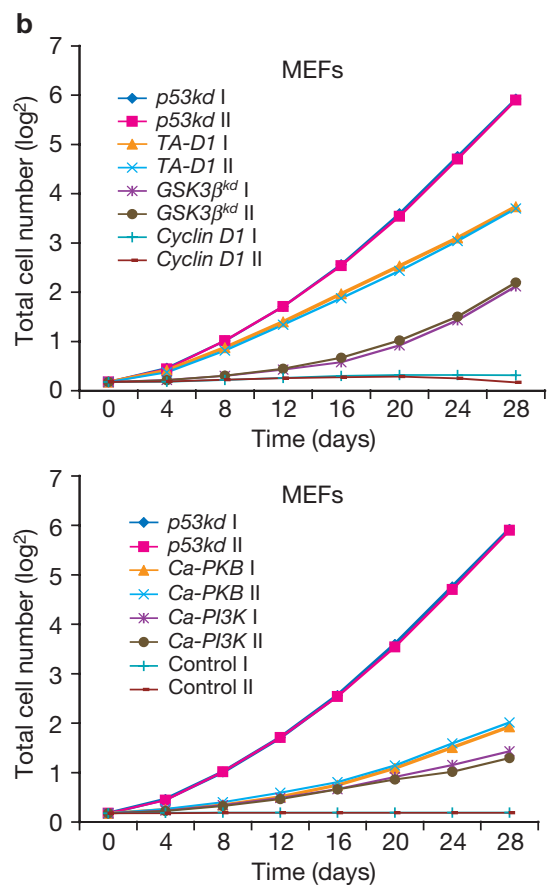

c

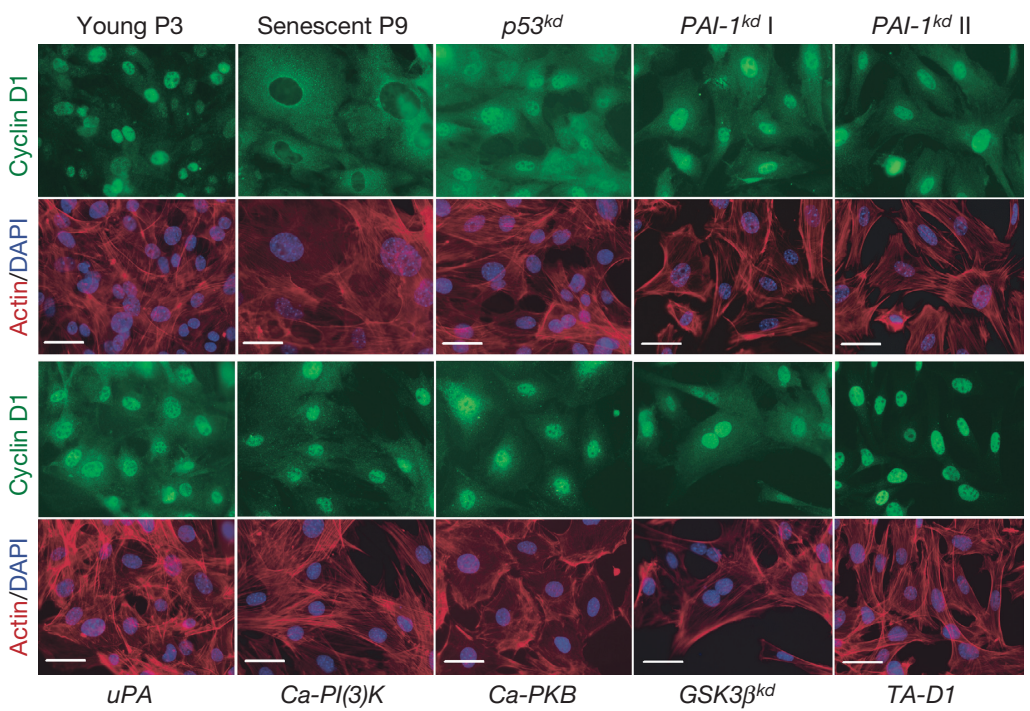

Figure 3 Sustained $\mathrm{PI}(3) \mathrm{K}-\mathrm{PKB}$ signalling or nuclear retention of cyclin D1 induces bypass of senescence. (a) Colony formation assay of primary MEFs infected with the indicated retroviral constructs. Immortalizing efficiency controls are $p 53^{k d}$ MEFs stained after 1 or 3 weeks. (b) Growth curves of various depicted immortalizing constructs versus wild-type cyclin D1 infected

MEFs. Overexpression of $p 53^{k d}$ or control vector are positive and negative controls, respectively. The results shown are of two independent infections per construct (I, II). (c) Qualitative immunofluorescence microscopy analysis for cyclin D1 of post-senescent MEFs immortalised with the indicated constructs and control P3 and P9 MEFs. The scale bar represents $50 \mu \mathrm{m}$.

efficiency (Fig. 5a). When the post-senescent and proliferating population doubling (PD) 68 PAI- $1^{\mathrm{kd}}$ were assayed for PAI-1 levels, reduction to levels even below those observed in young PD $30 \mathrm{BJ}$ fibroblasts was observed (Fig. 5b). PAI-1 levels in PD 68 uPA overexpressing BJ cells were similar to those seen in senescent cells, in agreement with the notion that $\mathrm{uPA}$ acts downstream of $\mathrm{p} 53$. PAI- $1^{\mathrm{kd}}$ or $\mathrm{uPA}$ overexpressing fibroblasts have notably higher levels of $p 21^{C I P 1}$ than $\mathrm{p} 53^{\mathrm{kd}}$ cells (Fig. 5b, c), consistent with the notion that PAI- $1^{\mathrm{kd}}$ mediates senescence-bypass downstream of p53. That $\mathrm{p} 53$ is wild type in the PAI- $1^{\mathrm{kd}}$ or uPA over-expressing BJ fibroblast is also supported by their normal response to DNA damage (data not shown). As observed in MEFs, induction of cyclin D1 in PAI- $1^{\mathrm{kd}}$ and uPA overexpressing post-senescent $\mathrm{BJ}$ cells, as well as in non-proliferating senescent BJ cells, was observed (Fig. 5c). Furthermore, an increase in cytoplasmic cyclin D1 in ageing BJ fibroblasts was noticed, which was associated with $\mathrm{p}^{2} 1^{\mathrm{CIP} 1}$ (see Supplementary Information, Fig. S4a-c), although the nuclear-to-cytoplasmic transition of cyclin D1 seems to be not as pronounced as in ageing MEFs. Importantly, overexpression of murine PAI-1, PTEN, or GSK3 $\beta$ in immortal human $\mathrm{p} 53^{\mathrm{kd}}$ or PAI- $1^{\mathrm{kd}}$ cells induced an arrest and SA- $\beta$-Gal. staining (Fig. $5 \mathrm{~d}$, e), indicating that PAI1 expression and downregulation of the PI(3)K-PKB-GSK3 $\beta$ signalling route are also sufficient for induction of senescence in human fibroblasts downstream of p53 and PAI-1. Taken together, we conclude that PAI-1 is necessary and sufficient for senescence in human BJ fibroblasts. As $p 21^{C I P 1}$ is an essential p53 target in the senescence response of human fibroblasts ${ }^{28,29}$, we asked if simultaneous knockdown of both $\mathrm{p}^{2} 1^{\mathrm{CIP} 1}$ and PAI-1 would induce a more efficient bypass of senescence than either one alone. Knockdown of the expression of either PAI-1 or $p 21^{C I P 1}$ resulted in a less efficient senescence-bypass than observed with knockdown of $p 53$ (see Supplementary Information, Fig. 5a, b). Interestingly, simultaneous knockdown of PAI-1 and $p 21^{C I P 1}$ resulted in a more efficient bypass of the arrest than knockdown of $p 53$ itself (see Supplementary Information, Fig. S5a-c). We conclude that PAI-1 and $\mathrm{p} 21^{\mathrm{CIP} 1}$ are both relevant downstream targets of $\mathrm{p} 53$ in the induction of senescence in human fibroblasts, as evident from the effects of their combined knockdown. 


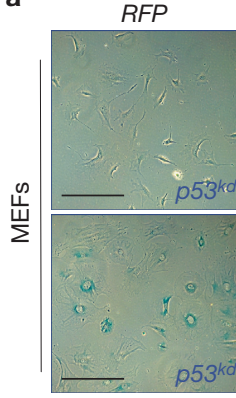

GSK3 $\beta$

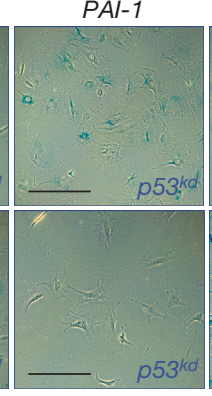

Starved

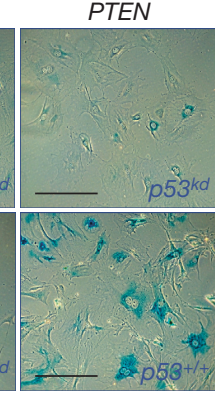

Senescent b

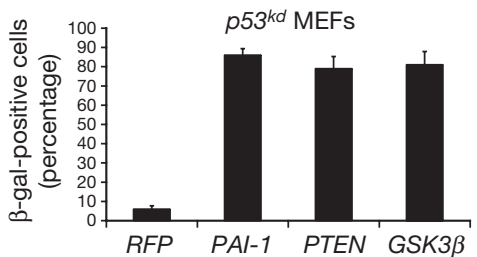

C

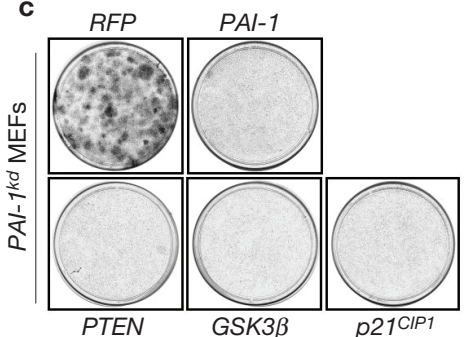

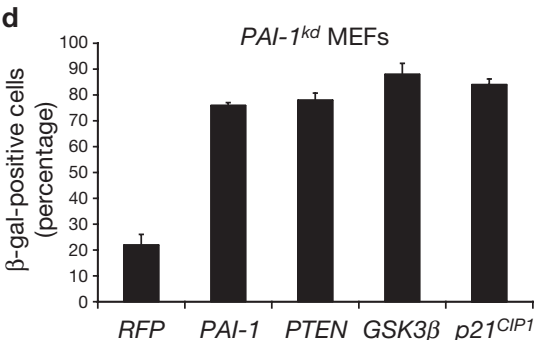

Figure 4 PAl-1 expression is sufficient for the induction of replicative senescence. (a) PAI-1, PTEN or GSK3 $\beta$ overexpression induces senescence in $p 53^{\text {kd }} \mathrm{MEFs}$ as indicated by staining for senescence-associated $\beta$-galactosidase (SA- $\beta$-Gal). Control cells are mock-infected, serum depleted (starved) and wild-type senescent MEFs. The scale bar represents $400 \mu \mathrm{m}$. (b) Quantification of SA- $\beta$-Gal-positive $p 53^{k d}$ cells after retroviral overexpression of constructs as indicated in $\mathbf{a}$. The mean \pm s.d. of three independent plates is shown. (c) Colony formation assay in immortal

Here, we show that PAI- 1 is a critical downstream target of p53 in the senescence response of both ageing mouse and human diploid fibroblasts. Our data indicate that $\mathrm{p} 53$ controls growth factor-dependent proliferation by upregulating PAI-1, leading to down-regulation of PI(3)K-PKB signalling and nuclear exclusion of cyclin D1. Conversely, we found that loss of PAI- 1 expression or UPA overexpression in MEFs conferred resistance to the anti-proliferative activity of $\mathrm{p} 53$ by inducing sustained $\mathrm{PI}(3) \mathrm{K}-\mathrm{PKB}$ signalling and cyclin D1 nuclear retention. Our data are consistent with a model in which PAI-1 acts to limit cyclin-CDK activity during the induction of replicative senescence and suggest a role for PAI-1 as a secreted gatekeeper of fibroblast proliferative capacity (Fig. 5f).

We found that the mitogen-stimulated $\mathrm{PI}(3) \mathrm{K}-\mathrm{PKB}$ pathway is causally involved in the senescence-bypass of fibroblasts, and that overexpression of its antagonist, PTEN ${ }^{22}$, can reverse this process. It has been reported that the levels of PTEN are crucial in determining the senescence response of fibroblasts - partial loss of PTEN confers a proliferative advantage, whereas acute loss of all PTEN induces senescence ${ }^{30}$. Consistent with this, we found that somatic knockdown of PTEN in wild-type MEFs resulted in bypass of senescence (data not shown) and constitutive activation of the $\mathrm{PI}(3) \mathrm{K}-\mathrm{PKB}$ signalling route, albeit not to the degree seen in $\mathrm{Ca}$ $\mathrm{PI}(3) \mathrm{K}$ or Ca-PKB overexpressing cells (see Supplementary Information, Fig. S3b). In apparent conflict with our data, which show senescence bypass by active $\mathrm{PKB}$, it has been reported that overexpression of an active $\mathrm{PKB}$ resulted in induction of senescence. However, when these cells were

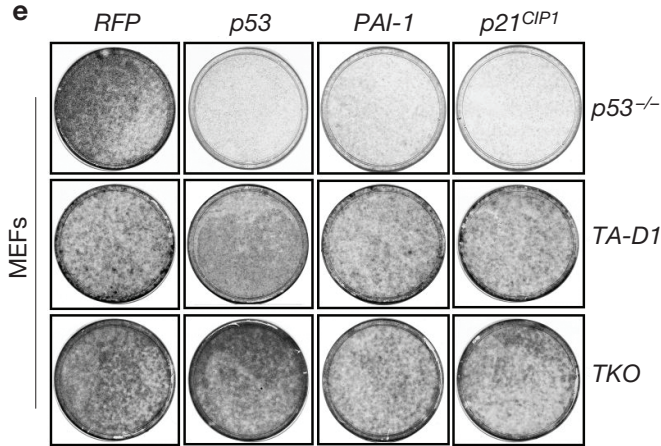

$P A /-1^{k d}$ MEFs after retroviral overexpression of the indicated constructs. $p 21^{C I P 1}$ and red fluorescent protein $(R F P)$ are positive and negative controls, respectively. (d) Quantification of SA- $\beta$-Gal-positive PAl- ${ }^{k d}$ MEFs after retroviral overexpression of PAI-1, PTEN, GSK3 $\beta, p 21^{C I P 1}$ or an RFP control. Shown is the mean \pm s.d. per plate per infection. (e) Colony formation assay in immortal $p 53^{-/}$, TA-D1 or TKO (retinoblastoma family triple knockout; $\left.p R b^{--}-p 107^{-1-}-p 130^{--}\right)$fibroblasts infected with indicated retroviral overexpression constructs.

followed over 6 days, proliferation was not entirely lost in the infected population ${ }^{30}$. We have selected PKB-infected wild type MEFs over a longer period of time, and consequently enriched for proliferating cells with potentially only moderately enhanced $\mathrm{PKB}$ activity. Taken together, these data support the notion that slightly elevated levels of $\mathrm{PKB}$ or partial loss of PTEN results in enhanced proliferation, whereas highly elevated $\mathrm{PKB}$ or complete loss of PTEN induces senescence. This is reminiscent of what has been observed in RAS signalling, where overexpression of an activated RAS oncogene induces senescence, whereas activated RAS expressed at physiological levels confers a growth advantage ${ }^{31}$.

$P A I-1$ is induced by a variety of growth factors and is a target of c$\mathrm{Myc}^{7,32}$. uPA transcription and its extracellular activity are regulated by growth-factor signalling and proteases. Induction of PAI-1 may therefore be part of a growth factor-stimulated negative feedback loop that becomes constitutively activated by $\mathrm{p} 53$ in ageing fibroblasts. As a consequence, senescent fibroblasts may induce a state of growth-factor unresponsiveness by secreting PAI-1. It is therefore possible that induction of PAI- 1 by 553 or disturbance of the uPA or PAI- 1 levels influences intra-tumour heterotypic signalling and the local tumour microenvironment. This is particularly noteworthy as uPA and PAI- 1 are causally involved in wound healing, angiogenesis and metastasis ${ }^{12,33}$ - processes that are dominantly regulated by cell-cell signalling ${ }^{34}$. Furthermore, uPA is secreted by stromal fibroblasts and myofibroblasts at the invasive front in breast and prostate cancer ${ }^{35}$ and loss of uPA can result in reduced 
a

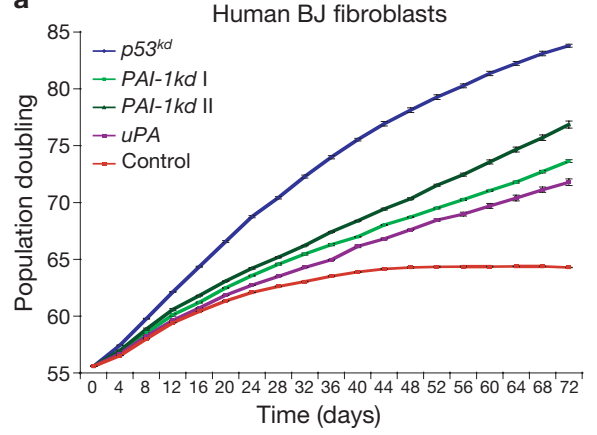

b

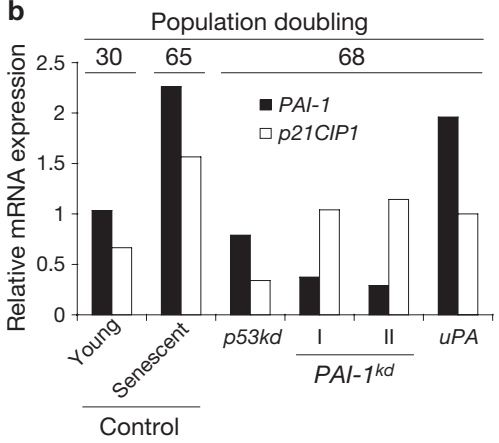

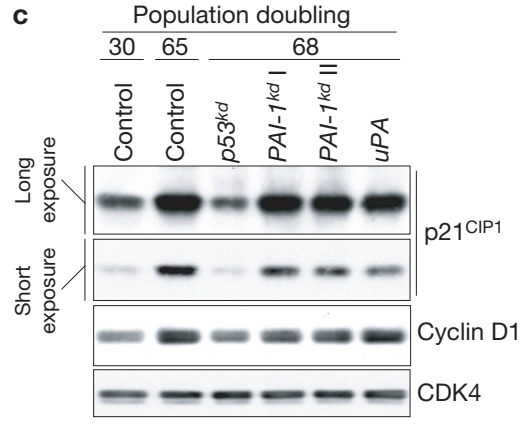

d

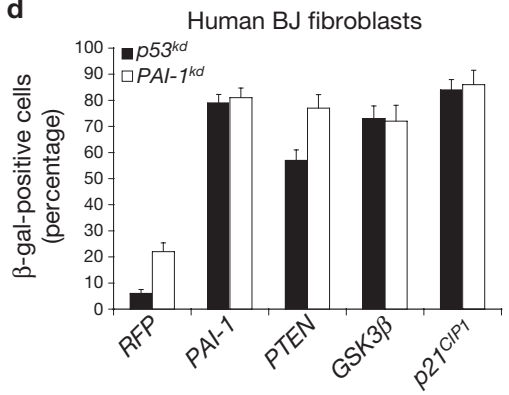

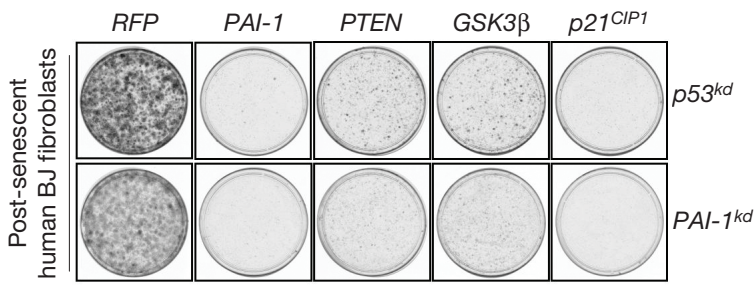

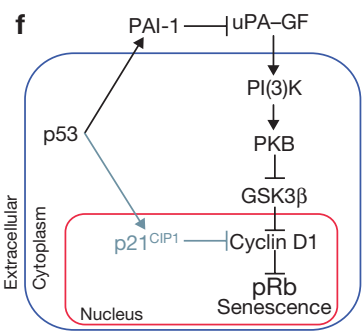

Figure 5 PAI-1 is necessary and sufficient for senescence in human BJ fibroblasts. (a) Growth curves of primary human BJ fibroblasts overexpressing the indicated constructs. The mean \pm s.d. of three independent cultures per genotype is shown. (b) Relative PAI- 1 and $p 21^{C I P 1}$ expression analysed by QRT$\mathrm{PCR}$ on the indicated post-senescent BJ cell lines and control-infected young or senescent BJ fibroblasts. (c) Western blot analysis of cells from a for p53-target p21 $1^{\mathrm{CIP1}}$ and cell-cycle related protein cyclin D1. CDK4 is a loading control. (d) Quantification of SA- $\beta$-Gal-positive post-senescent $P A I-1^{k d}$ or $p 53^{k d} \mathrm{BJ}$ fibroblasts after retroviral overexpression of PAI-1, PTEN, GSK3 $\beta, p 21^{C I P 1}$ or an

metastasis in mouse models ${ }^{36,37}$. As it is becoming increasingly clear that stromal tissue is an indispensable player in neoplastic transformation and metastasis ${ }^{38,39}$, our observations may lead to a better understanding of the role of fibroblasts in cancer.

\section{METHODS}

Antibodies and Vectors. For western blotting, antibodies against $\mathrm{p} 16^{\mathrm{INK} 4 \mathrm{~A}}$ (M156), p21 ${ }^{\mathrm{CIP} 1}$ (F5, C19), SP1 (PEP2), cyclin D1 (H295, M20), cyclin E (M20), PCNA (PC-10), PKB-Akt1 (C20), p53 (DO-1), HA (Y11) and CDK4 (C22) were purchased from Santa Cruz Biotechnology (Santa Cruz, CA); anti p-PKB (Ser473; \#9271), anti p-GSK3 $\beta$ (Ser9; \#9336) and HSP90 (\#4874) from Cell Signalling (Beverly, MA); anti p19 ${ }^{\mathrm{ARF}}$ (Ab 80-100) from Abcam (Cambridge, UK); antiGSK3 $\beta$ (610201) from BD Pharmingen (San Jose, CA); anti phosphotyrosine (PY20) from Calbiochem (San Diego, CA); and anti p53 (Ab7) from Oncogene Research Products (Boston, MA). Flag-tagged mouse cDNAs for PAI-1, GSK3 $\beta$, PTEN or human PAI-1 were generated by PCR amplification and cloned into pLZRS-IRES-zeocin. Mouse cDNA for $u P A$ was generated by PCR amplification of pro-uPA and cloned into $\mathrm{pBABEpuro.} \mathrm{The} \mathrm{production} \mathrm{of} \mathrm{siRNAs} \mathrm{in} \mathrm{MEFs,} \mathrm{BJ}$ or tsLT-hTERT-BJ fibroblasts was achieved using the pRETRO-SUPER vector $^{11}$. For the generation of mouse PAI-1 knockdown constructs the following 19-mer sequences were used: PAI-1 I, 5'-GAACAAGAATGAGATCAGT-3'; PAI1 II, 5'-GTTGGGCATGCCTGACATG-3'. For the generation of human PAI-1 knockdown constructs the following 19-mer sequences were used: PAI-1 I, $5^{\prime}$ CTGACTTCACGAGTCTTTC-3'; PAI-1 II, 5'-CCTGGGAATGACCGACATG$3^{\prime}$. The 19-mer sequences used for knockdown of mouse $p 53$ or GSK3 $\beta$ have been described elsewhere ${ }^{40,41}$, as have the 19-mer sequences used for knockdown of human $p 53$ or $p 21^{C I P 1}$ (ref. 29). Control infections were performed with nonfunctional hairpin or red fluorescent protein (RFP) vectors.
RFP control. The mean \pm s.d. of three independent plates is shown. (e) Colony formation assay in post-senescent $p 53^{k d}$ or PAl- ${ }^{k d} \mathrm{BJ}$ fibroblasts infected with the indicated retroviral overexpression constructs. RFP is a negative control. (f) Schematic representation of a proposed model for senescence in fibroblasts. p53 induces PAl-1 and $p 21^{C I P 1}$ during ageing in culture. PAI- 1 antagonizes uPA-GF (growth factor) signalling to cyclin D1 through PI(3)K-PKB-GSK3 $\beta$ and $\mathrm{p} 21^{\mathrm{ClP} 1}$ blocks cyclin D1 activity directly. The PAI-1-cyclin D1 connection is dominant over $\mathrm{p} 21^{\mathrm{CIP} 1}$ activity and controls induction of the senescence response downstream of $\mathrm{p} 53$ and upstream of $\mathrm{pRb}$.

Cell culture, transfection and retroviral infection. MEFs, primary and tsLT hTERT human BJ fibroblasts and Phoenix cells were cultured in DMEM (Gibco, Carlsbad, CA) supplemented with $8 \%$ heat-inactivated fetal bovine serum (Perbo; PAA, Pasching, Austria), $2 \mathrm{mM}$ L-glutamine and penicillin-streptomycin (Gibco). Transfections were performed with the calcium-phosphate precipitation technique. Retroviral supernatants were produced by transfection of Phoenix packaging cells. Viral supernatants were filtered through a $45 \mu \mathrm{m}$ Millex HA filter (Millipore, Carrigtwohill, Ireland) and infections were performed in the presence of $4 \mu \mathrm{g} \mathrm{ml}^{-1}$ polybrene (Sigma, St Louis, MO). Drug selections in MEFs or BJs were performed with $1 \mu \mathrm{g} \mathrm{ml}{ }^{-1}$ puromycin, $50 \mu \mathrm{g} \mathrm{ml}^{-1}$ hygromycin or $100 \mu \mathrm{g} \mathrm{ml}^{-1}$ zeocin.

Colony-formation assays. Wild-type MEFs were infected with shRNA or cDNA constructs at P3, selected and at P5 $5 \times 10^{4}$ cells were seeded onto 10 - $\mathrm{cm}$ plates and stained after 3 weeks. p5 $3^{\mathrm{kd}}$ control MEFs $\left(5 \times 10^{4}\right)$ were seeded onto $10-\mathrm{cm}$ plates and stained after 1, 2 or 3 weeks. Immortal PAI- ${ }^{k d}$ MEFs were infected, after $72 \mathrm{~h}$ were plated under low density $\left(5 \times 10^{4}\right.$ cells in a 10 -cm plate $)$ and 2 weeks were later stained. $p 53^{---}$, TA-D1 or TKO MEFs were infected, $48 \mathrm{~h}$ after infection $5 \times 10^{4}$ cells were seeded onto $10-\mathrm{cm}$ plates and were stained after 1 week. Human post-senescent $p 53^{k d}$ or PAI- $1^{k d}$ BJ fibroblasts were infected with cDNA constructs, plated under low density $\left(1 \times 10^{5}\right.$ cells in a $10-\mathrm{cm}$ plate $)$ and were stained after 2 weeks. Human tsLT BJ fibroblasts were infected at $32^{\circ} \mathrm{C}$ and after $48 \mathrm{~h}, 1 \times 10^{5}$ cells were seeded per 10 -cm plate, shifted to $39^{\circ} \mathrm{C}$ and stained after 2 weeks. For all colony formations representative examples of at least three independent experiments are shown.

Growth curves. MEFs were infected with retroviral shRNA or cDNA expression constructs at P3, selected and at P5 $1.5 \times 10^{5}$ cells were plated in a 6-cm dish (time $=0$ days). Every 4 days, cells were counted and $1.5 \times 10^{5}$ cells were replated. A MEF passage, as defined for this paper, represents 4 days in culture. PAI-1/-, 
$p 53^{-/-}$or wild-type MEFs $\left(1.5 \times 10^{5}\right)$ were plated in a $6-\mathrm{cm}$ dish at $\mathrm{P} 1$, and every 4 days cells were counted and $1.5 \times 10^{5}$ cells were replated. Human primary BJ fibroblasts at population-doubling 53 were infected, selected and $1.5 \times 10^{5}$ cells were plated in a $6-\mathrm{cm}$ dish (time $=0$ days). Every 4 days, cells were counted and $1.5 \times 10^{5}$ cells were replated. Human tsLT BJ fibroblasts were infected, shifted to $39^{\circ} \mathrm{C}$ after $48 \mathrm{~h}$ and $1.5 \times 10^{5}$ cells were plated in a $6-\mathrm{cm}$ dish (time $=0$ days). Every 6 days, cells were counted and $1.5 \times 10^{5}$ cells were replated. The p53 status of control, senescent or post-senescent primary MEFs, BJ fibroblasts or tsLT BJ fibroblasts was checked by DNA-damage induced p53 activation by overnight addition of $0.5 \mathrm{mM}$ cisplatin and western blotting for $\mathrm{p} 53$ and its targets (p19 $9^{\mathrm{ARF}}$ and $\mathrm{p} 21^{\mathrm{CIP1}}$ in MEFs, or $\mathrm{p} 21^{\mathrm{CIP1}}$ and Bax in BJ fibroblasts). Total cell amounts in all growth curves were displayed as cumulative over time. For all growth-curves representative examples of at least two independent experiments are shown.

Quantitative RT-PCR. Total RNA from immortal post-senescent MEF cell lines plus $\mathrm{P} 3$ and 9 control MEFs, control or immortalized human $\mathrm{BJ}$ fibroblasts and immortalised tsLT BJ fibroblasts at $39^{\circ} \mathrm{C}$ or controls at $32^{\circ} \mathrm{C}$ or $39^{\circ} \mathrm{C}$, was isolated with TRI-Zol (Invitrogen, Carlsbad, CA) according to manufacturers' instructions. QRT-PCR was performed on an ABI Prism 7700 with Assays-onDemand (Applied Biosystems, Foster City, CA) for mouse PAI-1 and TBP as a control housekeeping gene, or for human $P A I-1$ or $p 21^{C I P 1}$ with GAPDH as a control housekeeping gene. QRT-PCR results in tsLT BJ fibroblasts are the mean $\pm \mathrm{s}$. d. of three independent cell lines per genotype. For all QRT-PCRs, representative examples of at least two independent experiments are shown.

Immunofluorescence microscopy. Cells were plated on 8-well chamber slides (Nutacon; Leimuiden, The Netherlands) and cultured overnight after which they were fixed with $4 \%$ formaldehyde in PBS for $15 \mathrm{~min}$, permeabilized with $0.2 \%$ Triton X (Sigma), blocked and incubated with anti-cyclin D1 (M20) from Santa Cruz Biotechnology. Actin was stained with rhodamine-conjugated phalloidin (Invitrogen) and the nucleus with DAPI (Roche, Basel, Switzerland). Images were obtained using a Modified Zeiss Axiovert 100M (SP LSM 5) cooled CCD fluorescence microscope with a Plan-APOCHROMAT, 1.0 NA, 40× oil immersion objective plus a Zeiss single excitation-triple emission filter set 40 with a KP650 red blocking filter on a Photometrics MAC 200A camera and SmartCapture V2.0 software. For all immunostainings, representative examples of at least three independent experiments are shown.

Acidic $\beta$-galactosidase staining. $p 53^{k d}$ or PAI- $1^{k d}$ MEFs were infected, after 4 days plated under low density $\left(5 \times 10^{4}\right.$ cells in a $10-\mathrm{cm}$ plate $)$ and $24 \mathrm{~h}$ later stained overnight for senescence-associated acidic $\beta$-galactosidase as previously described ${ }^{21}$. Human post-senescent immortal $p 53^{k d}$ or PAI-1 ${ }^{k d}$ BJ fibroblasts were infected, after 5 days plated under low density $\left(1 \times 10^{5}\right.$ cells in a $10-\mathrm{cm}$ plate), and $48 \mathrm{~h}$ later stained overnight for acidic $\beta$-galactosidase as previously described $^{21}$. Per plate, three independent groups of 300 cells were counted for SA- $\beta$-Gal staining. For all SA- $\beta$-Gal stainings, representative examples of at least two independent experiments are shown. Images were obtained using a Zeiss Axiovert 25 microscope with A-Plan 10× or LD A-plan 20× objectives on a Canon Powershot G3 14× zoom camera.

Western blotting. Selected cells were lysed in RIPA buffer (50 mM Tris at pH 8, $150 \mathrm{mM} \mathrm{NaCl}, 1 \% \mathrm{NP} 40,0.5 \%$ deoxycholate, $0.1 \%$ SDS). 20,40 or 80 micrograms of Proteins $(20,40 \mathrm{or} 80 \mu \mathrm{g})$ were separated by $8-12 \%$ SDS-PAGE and transferred to polyvinylidine difluoride membranes (Millipore, Billerica, MA). Western blots were probed with the indicated antibodies. For all western blots representative examples of at least two independent experiments are shown.

Coimmunoprecipitations. Total cell lysates were isolated with ELB buffer $(0.25 \mathrm{M}$ $\mathrm{NaCl}, 0.1 \% \mathrm{NP} 40,50 \mathrm{mM}$ HEPES at $\mathrm{pH}$ 7.3) supplemented with Complete protease inhibitors (Roche). Cytoplasmic fractions of $\mathrm{BJ}$ cells were isolated with nuclear and cytoplasmic extraction kit NE-PER (Pierce Biotechnology Inc., Rockford, IL) according to manufacturers' instructions. Lysates were incubated with protein-A-Sepharose beads (Amersham-Pharmacia Biotech, Piscataway, NJ) coated with anti-cyclin D1 (M20, Santa Cruz Biotechnology). Analysis of cyclin D1 or cyclin D1-associated proteins was performed by western blotting the precipitates from cytoplasmic and total lysates.

Note: Supplementary Information is available on the Nature Cell Biology website.

\section{ACKNOWLEDGEMENTS}

We would like to thank A. Visser for technical assistance, K. Berns, M. Hijmans, A. Dirac, T. Brummelkamp, R. Agami, R. van der Kammen, J. Collard and F Scheeren for retroviral constructs, B. Weigelt for help with QRT-PCR, F. Foijer for retinoblastoma family deficient MEFs, L. Oomen and L. Brocks for help with microscopy, and R. Beijersbergen and D. Peeper for helpful discussions. This work was supported by a grant from the Dutch Cancer Society to R.B. and a grant from the National Institutes of Health (NIH; GM57242) to P.H.

\section{AUTHOR CONTRIBUTIONS}

R.K. and R.B. conceived and designed the experiments. R.K. performed the experiments. P.H. contributed materials. R.K. and R.B. analysed the data. R.K. and R.B. wrote the paper.

\section{COMPETING FINANCIAL INTERESTS}

The authors declare that they have no competing financial interests.

Published online at http://www.nature.com/naturecellbiology/

Reprints and permissions information is available online at http://npg.nature.com/ reprintsandpermissions/

1. Lundberg, A. S., Hahn, W. C., Gupta, P. \& Weinberg, R. A. Genes involved in senescence and immortalization. Curr. Opin. Cell Biol. 12, 705-709 (2000).

2. Sherr, C. J. \& McCormick, F. The RB and p53 pathways in cancer. Cancer Cell 2, 103-112 (2002).

3. Massague, J. G1 cell-cycle control and cancer. Nature 432, 298-306 (2004).

4. Pantoja, C. \& Serrano, M. Murine fibroblasts lacking p21 undergo senescence and are resistant to transformation by oncogenic Ras. Oncogene 18, 4974-4982 (1999).

5. Kunz, C., Pebler, S., Otte, J. \& von der Ahe, D. Differential regulation of plasminogen activator and inhibitor gene transcription by the tumor suppressor p53. Nucleic Acids Res. 23, 3710-3717 (1995).

6. Zhao, R. et al. Analysis of p53-regulated gene expression patterns using oligonucleotide arrays. Genes Dev. 14, 981-993 (2000)

7. Mu, X. C. \& Higgins, P. J. Differential growth state-dependent regulation of plasminogen activator inhibitor type-1 expression in senescent IMR-90 human diploid fibroblasts. J. Cell Physiol. 165, 647-657 (1995)

8. Martens, J. W. et al. Aging of stromal-derived human breast fibroblasts might contribute to breast cancer progression. Thromb. Haemost. 89, 393-404 (2003).

9. Serrano, M., Lin, A. W., McCurrach, M. E., Beach, D. \& Lowe, S. W. Oncogenic ras provokes premature cell senescence associated with accumulation of p53 and p16INK4a. Cell 88, 593-602 (1997).

10. De Petro, G., Copeta, A. \& Barlati, S. Urokinase-type and tissue-type plasminogen acti vators as growth factors of human fibroblasts. Exp. Cell Res. 213, 286-294 (1994).

11. Brummelkamp, T. R., Bernards, R. \& Agami, R. Stable suppression of tumorigenicity by virus-mediated RNA interference. Cancer Cel/ 2, 243-247 (2002).

12. Andreasen, P. A., Egelund, R. \& Petersen, H. H. The plasminogen activation system in tumor growth, invasion, and metastasis. Cell Mol. Life Sci. 57, 25-40 (2000).

13. Choong, P. F. \& Nadesapillai, A. P. Urokinase plasminogen activator system: a multifunctional role in tumor progression and metastasis. Clin. Orthop. 415, S46-S58 (2003).

14. Quelle, D. E. et al. Cloning and characterization of murine p16INK4a and p15INK4b genes. Oncogene 11, 635-645 (1995).

15. Linardopoulos, S. et al. Deletion and altered regulation of p16INK4a and p15INK4b in undifferentiated mouse skin tumors. Cancer Res. 55, 5168-5172 (1995).

16. Sherr, C. J. Tumor surveillance via the ARF-p53 pathway. Genes Dev. 12, 2984-2991 (1998).

17. Cross, D. A., Alessi, D. R., Cohen, P., Andjelkovich, M. \& Hemmings, B. A. Inhibition of glycogen synthase kinase-3 by insulin mediated by protein kinase B. Nature $\mathbf{3 7 8}$ 785-789 (1995).

18. Vivanco, I. \& Sawyers, C. L. The phosphatidylinositol 3-Kinase AKT pathway in human cancer. Nature Rev. Cancer 2, 489-501 (2002).

19. Diehl, J. A., Cheng, M., Roussel, M. F. \& Sherr, C. J. Glycogen synthase kinase-3ß regulates cyclin D1 proteolysis and subcellular localization. Genes Dev. 12, 34993511 (1998).

20. Chandrasekar, N. et al. Downregulation of UPA inhibits migration and PI3k/Akt signaling in glioblastoma cells. Oncogene 22, 392-400 (2003)

21. Dimri, G. P. et al. A biomarker that identifies senescent human cells in culture and in aging skin in vivo. Proc. Natl Acad. Sci. USA 92, 9363-9367 (1995).

22. Parsons, R. Human cancer, PTEN and the PI-3 kinase pathway. Semin. Cell Dev. Biol. 15, 171-176 (2004)

23. Radu, A., Neubauer, V., Akagi, T., Hanafusa, H. \& Georgescu, M. M. PTEN induces cell cycle arrest by decreasing the level and nuclear localization of cyclin D1. Mol. Cell Biol. 23, 6139-6149 (2003)

24. Dannenberg, J. H., van Rossum, A., Schuijff, L. \& te Riele, H. Ablation of the retinoblastoma gene family deregulates $\mathrm{G}(1)$ control causing immortalization and increased cell turnover under growth-restricting conditions. Genes Dev. 14, 3051-3064 (2000).

25. Sage, J. et al. Targeted disruption of the three Rb-related genes leads to loss of G(1) control and immortalization. Genes Dev. 14, 3037-3050 (2000).

26. Rowland, B. D. et al. E2F transcriptional repressor complexes are critical downstream targets of p19(ARF)/p53-induced proliferative arrest. Cancer Cel/ 2, 55-65 (2002).

27. West, M. D., Shay, J. W. Wright, W. E. \& Linskens, M. H. Altered expression of plasminogen activator and plasminogen activator inhibitor during cellular senescence. Exp. Gerontol. 31, 175-193 (1996) 


\section{LETTERS}

28. Brown, J. P., Wei, W. \& Sedivy, J. M. Bypass of senescence after disruption of p21CIP1/ WAF1 gene in normal diploid human fibroblasts. Science 277, 831-834 (1997).

29. Berns, K. et al. A large-scale RNAi screen in human cells identifies new components of the p53 pathway. Nature 428, 431-437 (2004).

30. Chen, Z. et al. Crucial role of p53-dependent cellular senescence in suppression of Pten-deficient tumorigenesis. Nature 436, 725-730 (2005).

31. Tuveson, D. A. et al. Endogenous oncogenic K-ras(G12D) stimulates proliferation and widespread neoplastic and developmental defects. Cancer Cel/ 5, 375-387 (2004).

32. Prendergast, G. C., Diamond, L. E., Dahl, D. \& Cole, M. D. The c-myc-regulated gene $m r l$ encodes plasminogen activator inhibitor 1. Mol. Cell Biol. 10, 1265-1269 (1990).

33. Parfyonova, Y. V., Plekhanova, O. S. \& Tkachuk, V. A. Plasminogen activators in vascular remodeling and angiogenesis. Biochemistry (Mosc) 67, 119-134 (2002).

34. Bissell, M. J. et al. Tissue structure, nuclear organization and gene expression in normal and malignant breast. Cancer Res. 59, S1757-S1763 (1999).

35. Usher, P. A. et al. Expression of urokinase plasminogen activator, its receptor and type-1 inhibitor in malignant and benign prostate tissue. Int. J. Cancer 113, 870-880 (2005). 36. Frandsen, T. L. et al. Direct evidence of the importance of stromal urokinase plasminogen activator (UPA) in the growth of an experimental human breast cancer using a combined uPA gene-disrupted and immunodeficient xenograft model. Cancer Res. 61, 532-537 (2001).

37. Almholt, K. et al. Reduced metastasis of transgenic mammary cancer in urokinasedeficient mice. Int. J. Cancer 113, 525-532 (2005).

38. Tuxhorn, J. A., Ayala, G. E. \& Rowley, D. R. Reactive stroma in prostate cancer progression. J. Urol. 166, 2472-2483 (2001).

39. Mueller, M. M. \& Fusenig, N. E. Friends or foes - bipolar effects of the tumour stroma in cancer. Nature Rev. Cancer 4, 839-849 (2004).

40. Dirac, A. M. \& Bernards, R. Reversal of senescence in mouse fibroblasts through lentiviral suppression of p53. J. Biol. Chem. 278, 11731-11734 (2003).

41. Yu, J. Y., Taylor, J., DeRuiter, S. L., Vojtek, A. B. \& Turner, D. L. Simultaneous inhibition of GSK3 $\alpha$ and GSK3 $\beta$ using hairpin siRNA expression vectors. Mol. Ther. 7 228-236 (2003). 


\section{Supplementary Figure S1}

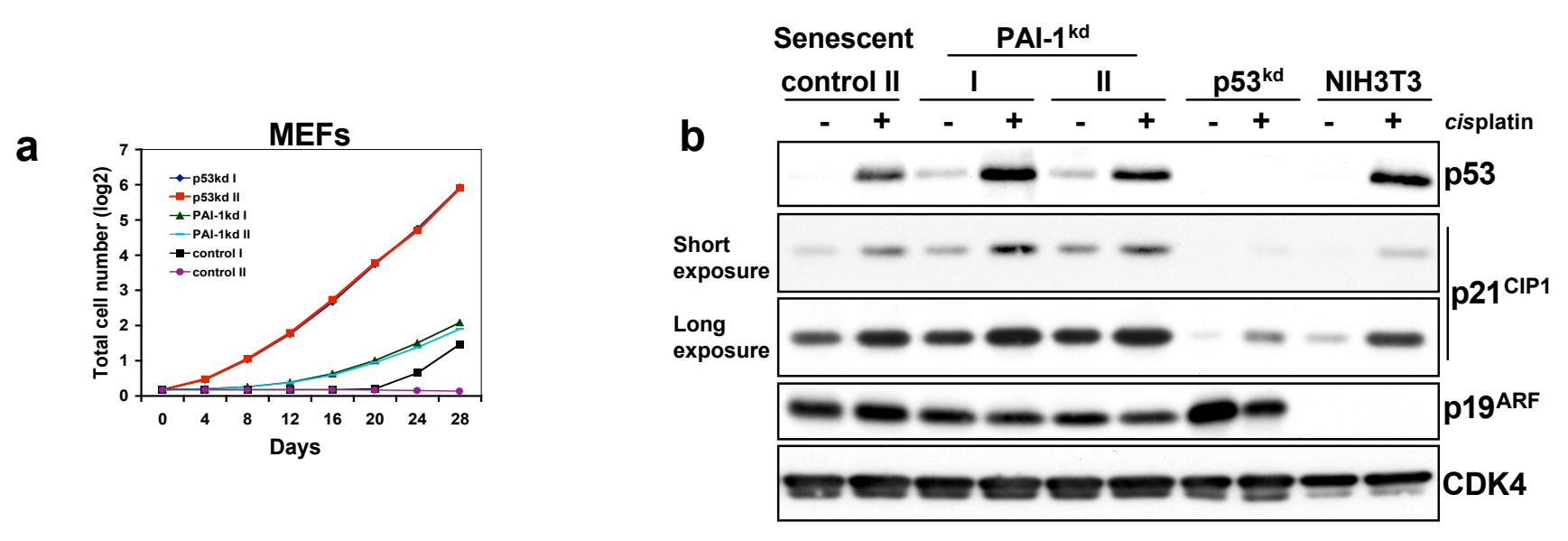

Supplementary Figure S1 PAI- $1^{\mathrm{kd}}$ induces senescence-bypass in primary MEFs retaining p1 ${ }^{\text {ARF }}$-p53 signalling .

(a) Long-term proliferation curves of $\mathrm{p} 53^{\mathrm{kd}}, \mathrm{PAl}-1^{\mathrm{kd}}$, or non-functional shRNA control infected MEFs. Shown are the results of two

independent experiments per construct $(\mathrm{I}, \mathrm{II})$.

(b) Western blot analysis for p53 and its targets p1 $9^{\mathrm{ARF}}$ and $\mathrm{p} 21^{\mathrm{CIP} 1}$ using cell lines depicted in (a) after cisplatin-induced DNA-damage.

NIH3T3 cells are immortal p16 $6^{\text {INK4A }} / \mathrm{p} 19^{\text {ARF }}$-deficient controls. 
Supplementary Figure S2
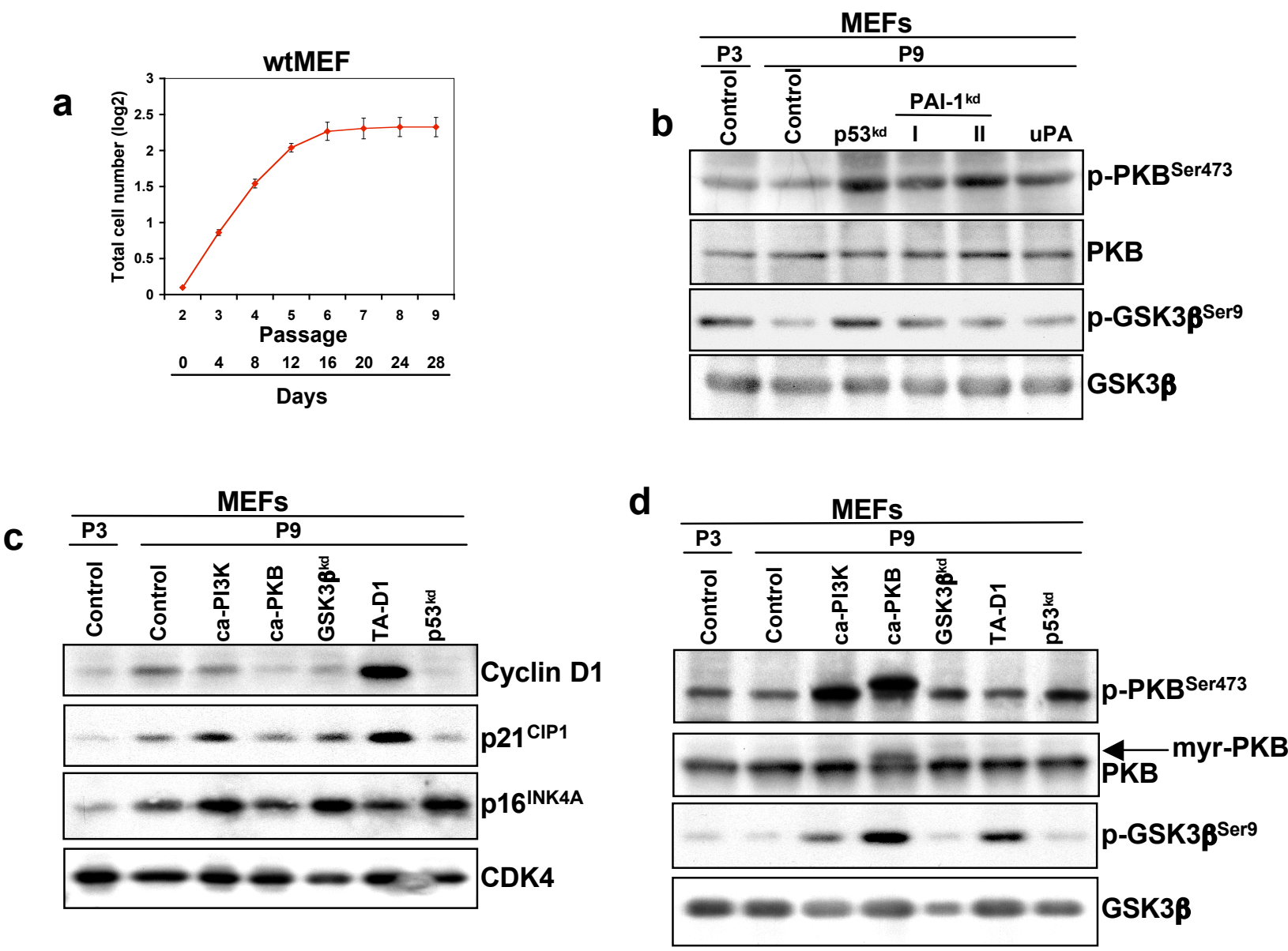

e

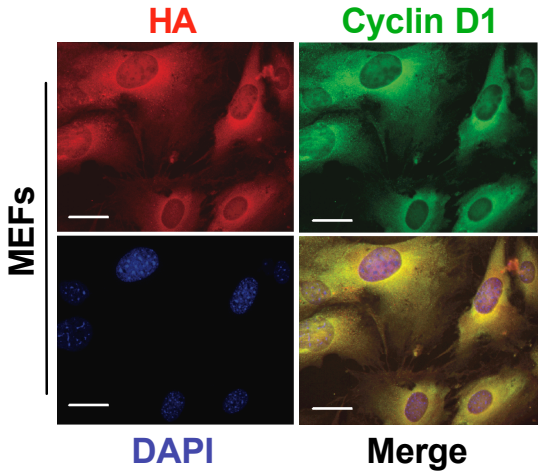

Supplementary Figure S2 Retention or induction of PKB-GSK3 $\beta$ signalling in immortal MEFs.

(a) Proliferation curves of 6 independently isolated cultures of wild-type MEFs. Mean value (+/- SD) is indicated.

(b) Expression of phosphorylated PKB or GSK3 $\beta$ related to unphosphorylated fraction of the same proteins in P3, P9, p53 $3^{\mathrm{kd}}$, PAl-1 ${ }^{\mathrm{kd}}$, or uPA over-expressing cells as analyzed by western blot.

(c) Western blots of protein samples of indicated cell lines with antibodies for tumour suppressors p16 ${ }^{\mathrm{INKAA}}$ or p21 ${ }^{\mathrm{CIP} 1}$, or cyclin D1. CDK4 is a loading control.

(d) Western blots for the same set of cell lines as in (c) for phospho-specific PKB and GSK3 $\beta$, as compared to unphosphorylated fractions of the same proteins.

(e) Qualitative immunofluorescence analysis for HA-tag (HA) and cyclin D1 in senescent MEFs over-expressing HA-tagged cyclin D1. Bar represents $50 \mu \mathrm{m}$. 


\section{Supplementary Figure S3}
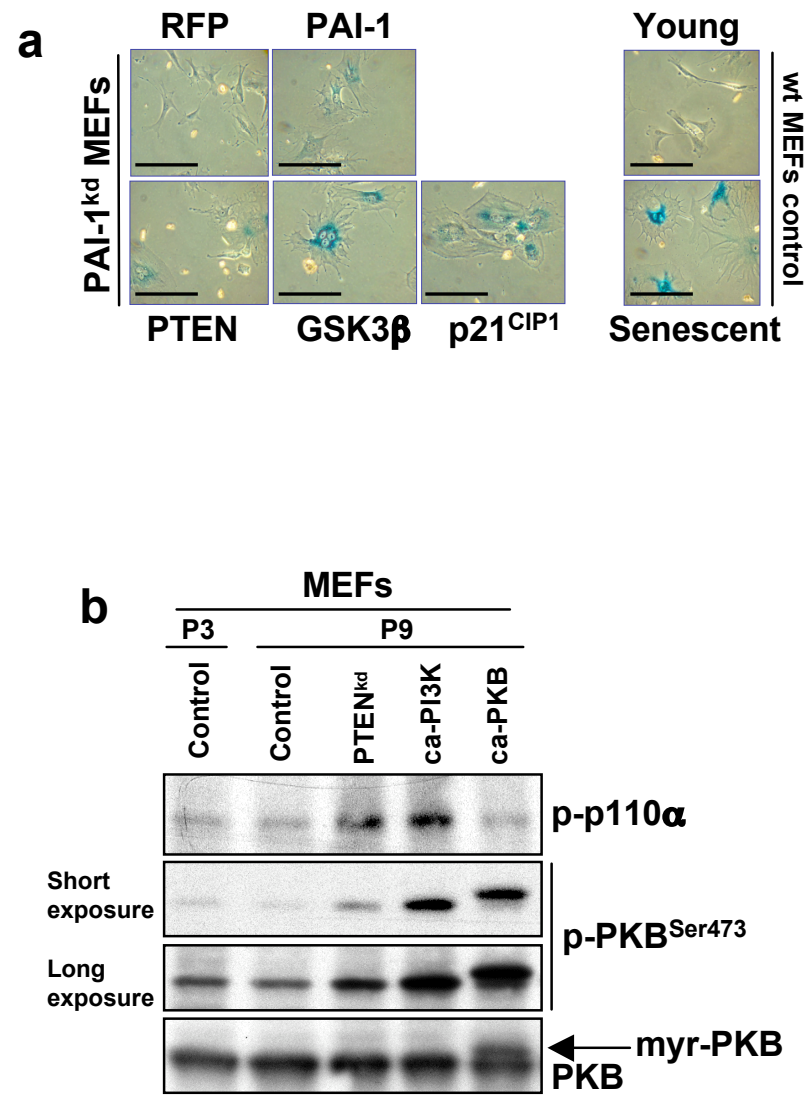

Supplementary Figure S3 PAl-1 is sufficient for induction of senescence in MEFs.

(a) PAl-1, PTEN, GSK3 $\beta$, or p2 $1^{\mathrm{ClP} 1}$ over-expression induces senescence in PAl-1 ${ }^{\mathrm{kd}}$ MEFs as indicated by staining for senescence-

associated $\beta$-galactosidase (SA- $\beta$-Gal). Staining controls are young and senescent wild-type MEFs. Scale bar represents $250 \mu \mathrm{m}$.

(b) Expression of phosphorylated $\mathrm{p} 110 \alpha$ (catalytic subunit of PI3K) and PKB related to unphosphorylated fraction of the same protein in P3,

P9, PTEN ${ }^{\mathrm{kd}}$, ca-PI3K or ca-PKB over-expressing cells as analyzed by western blot. 


\section{Supplementary Figure S4}

a

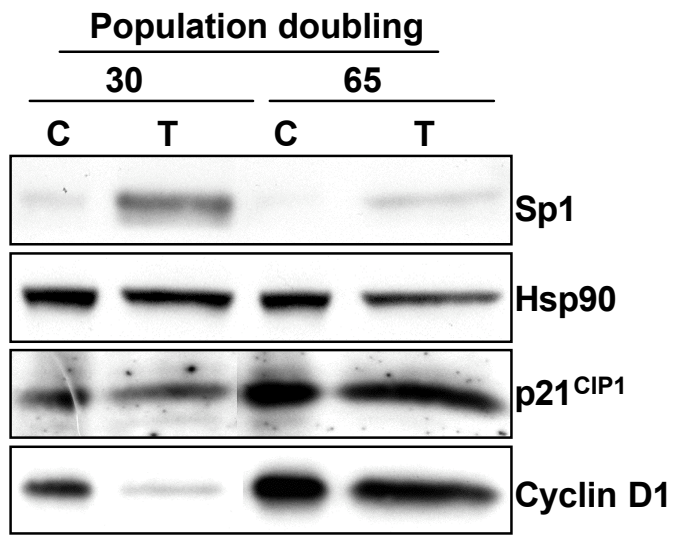

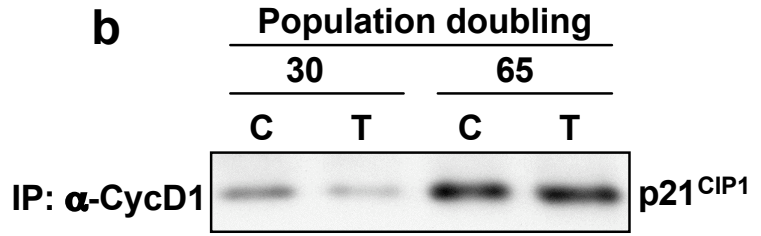

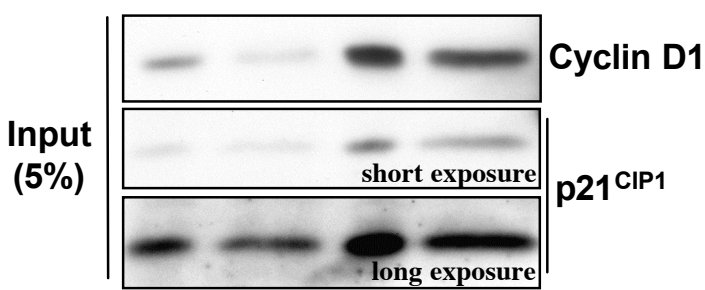

C

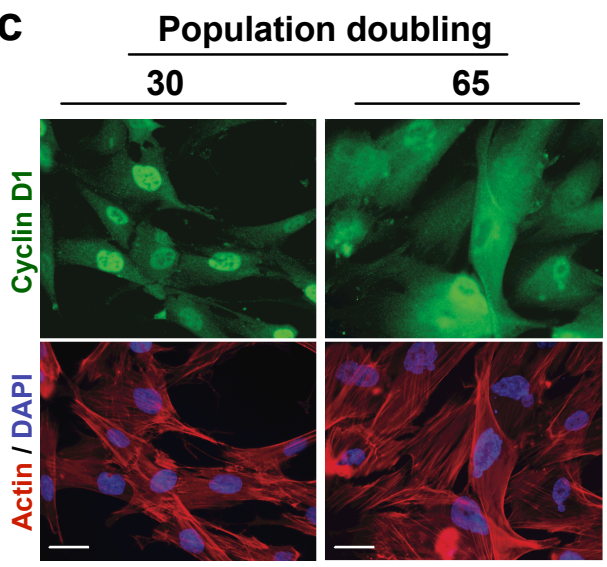

d

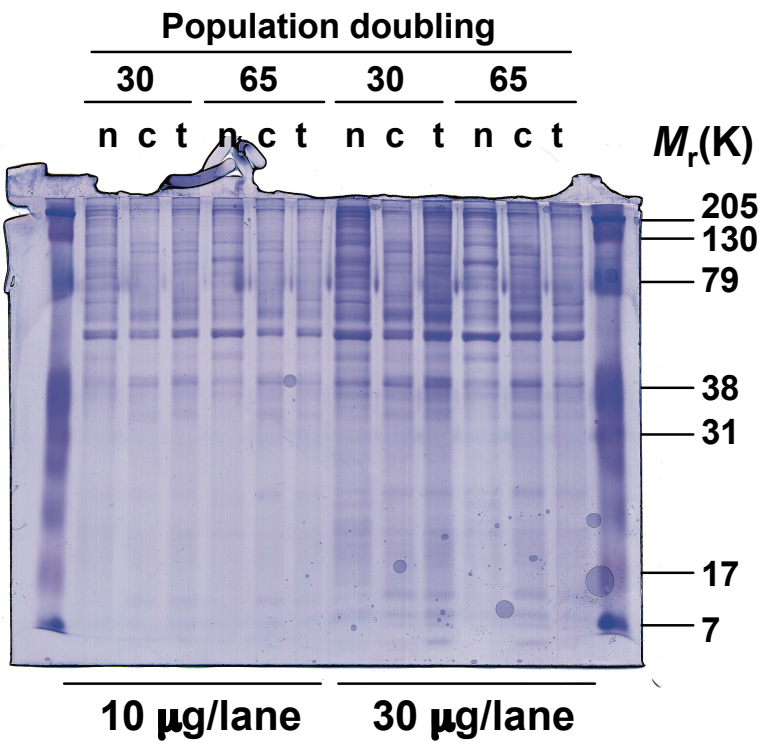

Supplementary Figure S4 Cytoplasmic co-localization of cyclin D1 and p21 ${ }^{\mathrm{ClP} 1}$ in ageing primary BJ fibroblasts.

(a) Western blot of cytoplasmic $(C)$ and total $(T)$ protein lystates from primary young passage doubling 30 and senescent passage doubling

$65 \mathrm{BJ}$ fibroblasts probed for indicated proteins. Sp1 is a nuclear protein and Hsp90 a cytoplasmic fraction control.

(b) Immunoprecipitation with cyclin D1 antibody in protein lysates from (a) immunoblotted for p21 ${ }^{\mathrm{CIP} 1}$.

(c) Qualitative immunofluorescence analysis of serially passaged BJs, passage doubling 30 or passage doubling 65 , for cyclin D1 expression. Bar represents 50 um.

(d) Coomassie staining of SDS gel with 10 or $30 \mu \mathrm{g}$ of nuclear (n), cytoplasmic (c) or total (t) protein from young populatipon doubling (PD)

30 or senescent PD 65 primary BJ fibroblasts, for equal loading. 


\section{Supplementary Figure S5}

a

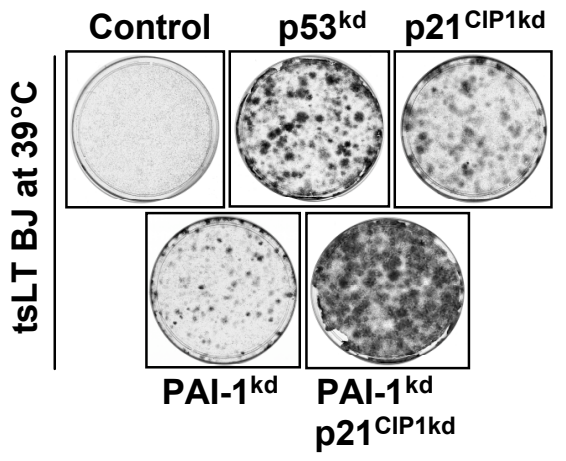

b

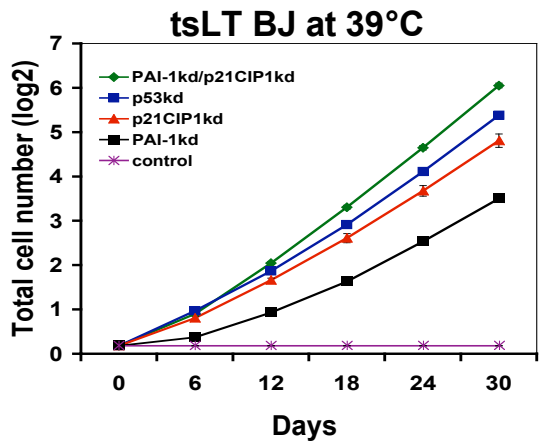

C

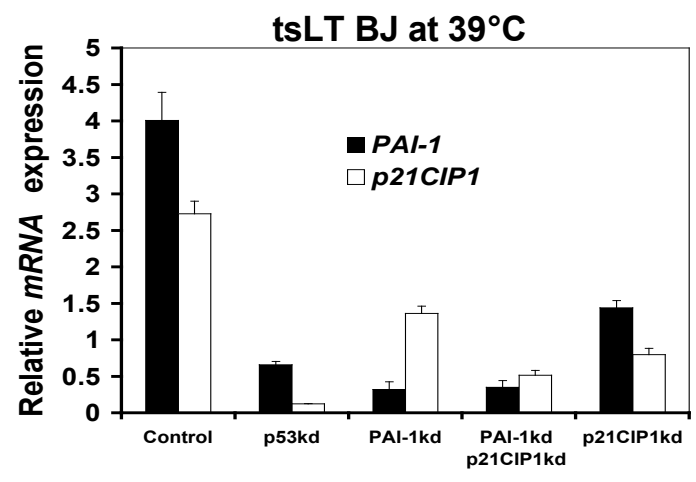

Supplementary Figure S5 PAI-1 and p2 $1^{\mathrm{ClP} 1}$ collaborate in senescence response downstream of p53.

(a) Colony formation assay of depicted constructs in conditionally immortalized tsLT hTERT BJ fibroblasts ${ }^{29}$. Control is a non-functional shRNA. These cells enter into a p53-dependent proliferation arrest when shifted to the non-permissive temperature $\left(39^{\circ} \mathrm{C}\right)$. Importantly, these cells show virtually exact characteristics as primary BJ fibroblasts when challenged through assays as described in Fig. 5a-e (data not shown).

(b) Long term growth curves at the non-permissive temperature of $39^{\circ} \mathrm{C}$ of cells over-expressing depicted constructs. Per genotype the mean (+/-SD) of 3 independent cultures is shown. PAl-1 and $p 21^{C / P 1}$ are both p53 target genes and knockdown of the expression of either gene alone results in a less efficient senescence bypass than seen with knockdown of p53 alone (see also (a)).

(c) Quantitative real-time PCR analysis of relative expression of $P A l-1$ and $p 21^{C l P 1}$ in cell lines depicted in (b). As in primary BJ fibroblasts (see Fig. $5 \mathrm{~b}$ ), we noticed reduction of PAI-1 mRNA in p2 ${ }^{\mathrm{CIP} 1 \mathrm{kd}}$ cells and reduction of $p 21^{C I P 1} \mathrm{mRNA}$ in PAI-1 ${ }^{\mathrm{kd}}$ cells, suggesting that loss of either gene influences transcription of the other. 